\title{
Effects of brass addition on the flexural strength and microstructure of porous clay/brass composites
}

\author{
Muh Amin ${ }^{1, *}$ Rubijanto Juni Pribadi ${ }^{1}$ and Jamasri ${ }^{2}$ \\ ${ }^{1}$ Mechanical Engineering Department, Universitas Muhammadiyah Semarang, 50273 Semarang, \\ Indonesia \\ ${ }^{2}$ Mechanical Engineering Department, Gadjah Mada University, 55281 Yogyakarta, Indonesia
}

\begin{abstract}
Porous clay/brass composite was fabricated by an extrusion process with the addition up to $40 \mathrm{wt} . \%$ brass has been successfully done. Clay 80 wt.\%, $\mathrm{TiO}_{2} 10$ wt.\%, active carbon 5 wt. $\%$, and polyvinyl alcohol 5 wt.\% have been prepared as a matrix for this study. All of wt.\% has been mentioned excluding solvent water $20 \mathrm{wt} . \%$ and lubricant (glycerin oil, 1 wt.\%). Before the moulding process, all the raw materials were mixed to obtain homogeneity. Blending process was done by adding $20 \mathrm{wt} \%$ water until the mixture turned into dough. After the moulding process, the specimens were dried at room temperature for 48 hours, and then they were sintered at $800^{\circ} \mathrm{C}$ for 1 hour in an electrical box furnace with heating rate $1{ }^{\circ} \mathrm{C} /$ min and holding time of 1 hour. The flexural strength of specimens and the microstructure of the sintered porous bodies were also investigated. The addition of $20 \mathrm{wt} . \%$ brass on the composite materials showed a higher on the strength, that is $0.6 \mathrm{MPa}$ and $0.38 \mathrm{MPa}$ on yield strength.
\end{abstract}

\section{Introduction}

One of the most widely used materials in the industry is a porous material. Porous materials were used as filtering and membranes. Generally, porous materials were produced from polymer, metal, ceramic and composite materials with various techniques. However, the membrane of the ceramic-based composite material has more coverage in various fields, such as for water and energy sustainability [1] water treatment and desalination [2] and separation process in chemical industry [3-5]. Some advantages of the ceramic membranes are (1) more effectives as disinfection precusor removal and (2) having higher permeability compared with equivalent polymeric membrane [6].

The commercial ceramic membranes are generally manufactured from industrial oxides such as $\mathrm{Al}_{2} \mathrm{O}_{3}$ and $\mathrm{SiO}_{2}$ exhibiting good mechanical, chemical and thermal resistance and a long lifetime, but their cost are relatively higher. In order to reduce their cost, research has been oriented to manufacture the ceramic membrane using cheaper raw materials [7] [8], such as local materials [9-12] and waste materials [13-15]. In addition, the selection of manufacturing methods also affects production costs. For mass production, the extrusion

\footnotetext{
* Corresponding author: amin@unimus.ac.id
} 
method is preferred. Extrusion method is a simple, important, and the mass production method of producing ceramic membranes. It has been extensively used for the fabrication of porous ceramic tubes. In this method, a homogeneous stiff paste is forced through a nozzle to be compacted or shaped to form the final green membrane. To keep the membrane in its desired final shape, any remaining binder, solvent, and plasticizer should be evaporated [16].

\section{Material and methods}

\subsection{Raw materials}

The raw materials used in this study were clay, $\mathrm{TiO}_{2}$, black carbon (BC), polyvinyl alcohol (PVA) and brass powder. They were similar as our research in the manufacture of porous ceramic membranes for micro-filtration [17]. This study is the subsequent effort of the previous studies related to porous ceramics [18], [19]. All materials were obtained from local place, Indonesia, except PVA which was imported from China. The clay from Pekalongan, Central Java, was used as a matrix in the manufacturing of samples (Table 1). These clays are representative and widely used by ceramic plant for the production of clay-based structural ceramics.

The reinforcement of composite material in this work is brass waste from craftsmen in Juwana, Central Java, Indonesia. Previously, the brass waste was carried out by sieving and drying treatment in order to obtain the material without impurities. After sieving using 100 mesh, the waste was sieved again by using 120 mesh. The material still left in 100 mesh was used as a composite reinforcement. After that, the brass powder was dried at $150^{\circ} \mathrm{C}$ for 2 hours.

Table 1. Chemical composition for each raw material used in this study

\begin{tabular}{|c|c|c|c|c|c|}
\hline \multirow{2}{*}{ Element } & \multicolumn{5}{|c|}{ Compound (\%) } \\
\cline { 2 - 6 } & Clay & TiO $_{2}$ & BC & PVA & Brass \\
\hline $\mathrm{C}$ & 16.96 & - & 75.49 & 95.91 & 3.29 \\
\hline $\mathrm{O}$ & 38.39 & 40.58 & 8.98 & 0.87 & 20.38 \\
\hline $\mathrm{Mg}$ & - & - & 0.53 & - & - \\
\hline $\mathrm{Al}$ & 1.49 & 2.48 & 1.80 & - & 1.33 \\
\hline $\mathrm{Si}$ & 1.74 & 0.67 & 4.05 & - & 0.66 \\
\hline $\mathrm{Cl}$ & - & - & 0,49 & - & - \\
\hline $\mathrm{K}$ & - & - & 2.57 & - & - \\
\hline $\mathrm{Ca}$ & - & - & 1.47 & - & - \\
\hline $\mathrm{Ti}$ & - & 56.26 & - & - & - \\
\hline $\mathrm{Fe}$ & - & - & 1,82 & - & - \\
\hline $\mathrm{Cu}$ & - & - & 2.13 & 3.90 & 57.07 \\
\hline $\mathrm{Zn}$ & - & - & & - & 20.33 \\
\hline $\mathrm{Na}$ & 2.44 & - & 0.65 & 0.65 & - \\
\hline
\end{tabular}

\subsection{Sample preparation}

The flexural strength for a range firing schedule of brass powder additions was determined for 10 test-samples. All specimens were prepared according to the standard of flexural strength testing based on ASTM Standard C158-95 [20]. While the raw materials used to make specimens were based on this study [21]. First, all raw materials except brass were sieved through 100 mesh. After that, they were mixed according to the comparison in Table 2. The addition of brass was done after the $\mathrm{X}$ material has been made. The $\mathrm{X}$ material consists of clay 80 wt. $\%, \mathrm{TiO}_{2} 10$ wt. $\%, \mathrm{BC} 5$ wt. $\%$ and PVA 5 wt.\%. The mixing process of $1 \mathrm{~kg}$ 
raw materials was done by using ball milling for rotational speed of $62 \mathrm{rpm}$ for 1 hour. The next stage is the manufacturing of ceramic green body.

The process of making a green body was prepared using a dough of raw materials by adding the water as much as $15 \mathrm{wt} . \%$ of the raw material mixture. To obtain a homogeneous dough, a blending process was performed at $62 \mathrm{rpm}$ for 1 hour. After that, the dough was printed using the extrusion method. The extrusion punch emphasis was made of $25 \mathrm{MPa}$.

After waiting for 24 hours at room temperature, a green body was inserted into the furnace for sintering process. The sintering process was set at a temperature of $800^{\circ} \mathrm{C}$ (heating rate of $5^{\circ} \mathrm{C} / \mathrm{min}$ and holding time for 1 hour). After that, the temperature was decreased by turning off the furnace switch. Once at room temperature, the specimen was machined for surface finishing.

Table 2. The composition of the materials used in this study

\begin{tabular}{|c|c|c|c|c|c|}
\hline Abbreviation & Clay (wt.\%) & $\mathrm{TiO}_{2}$ (wt.\%) & BC (wt.\%) & PVA (wt.\%) & Brass (wt.\%) \\
\hline $\mathrm{A}$ & \multirow{5}{*}{80} & \multirow{5}{*}{10} & \multirow{5}{*}{$-(\log )$} & \multirow{5}{*}{5} & 0 \\
\hline B & & & & & 10 \\
\hline $\mathrm{C}$ & & & & & 20 \\
\hline $\mathrm{D}$ & & & & & 30 \\
\hline$E$ & & & & & 40 \\
\hline
\end{tabular}

\subsection{Flexural strength testing}

Flexural strength testing was based on ASTM Standard C158-95. Testing was done by using Universal Testing Machine (Zwick, Germany) at a crosshead speed of $1 \mathrm{~mm} / \mathrm{min}$ until failure. The specimens were tested at ambient temperature and dimensions were measured with a digital micrometer (Mitutoyo, Germany) heaving precision of $0.01 \mathrm{~mm}$.

The sample holder for the flexural strength test comprised three tempered steel balls with a diameter of $15 \mathrm{~mm}$. The steel balls formed an equilateral with an edge length of 25 $\mathrm{mm}$ and the ball support degree was $135^{\circ}$. The load was applied to the center of length on the top specimen by using a plunger with a diameter $1.3 \mathrm{~mm}$ until failure. The flexural strength was calculated according to the formula of Three-point bending (Eq. 1) [22] (P = load (N); $\mathrm{L}=$ distance among the support $(\mathrm{mm}) ; \mathrm{B}=$ width of the specimen $(\mathrm{mm})$ and $\mathrm{W}=$ high specimen $(\mathrm{mm}))$.

$$
\sigma_{M O R}=\frac{3 P L}{2 B W^{2}}
$$

\subsection{Scanning electron microscopy (SEM)}

Scanning electron microscopy (AVA MM 20, Germany) was used to observe the specimen surface $(15 \mathrm{kV}, 150 \mathrm{~mA}$, the working distance of $10-15 \mathrm{~mm})$. The specimens were ultrasonically cleaned (Sonorex RK $100 \mathrm{H}$; Germany) and gold coated (sputter coater SC76, Newhaven) before the SEM examination.

\section{Results}

The result of the flexural strength test used three-point bending method can be shown in Figure 1. Based on the data, the flexural strength of specimens has increased with the increasing of brass content up to $20 \mathrm{wt} . \%$. After that, the flexural strength has decreased. The highest flexural strength occurs in $20 \mathrm{wt} . \%$ of brass which was $0.6 \mathrm{MPa}$ and the yield was $0.38 \mathrm{MPa}$. 
The SEM images are shown in Figure 4. The addition of brass content of ceramic materials indicates a decrease in the number of porosities (Figure 2) and an increase of density (Figure 3). This is apparent in SEM images from various brass additions. With the decline of porosity, it can affect the magnitude of flexural strength composite material.

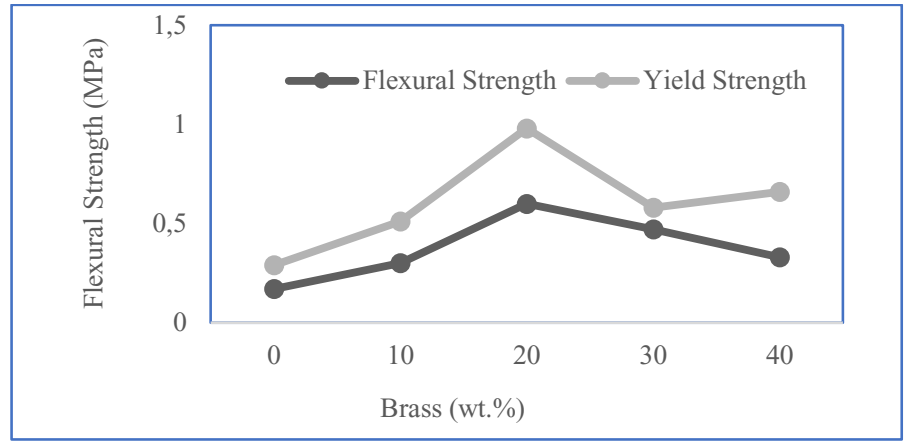

Fig. 1. Flexural strength of sintered specimen.

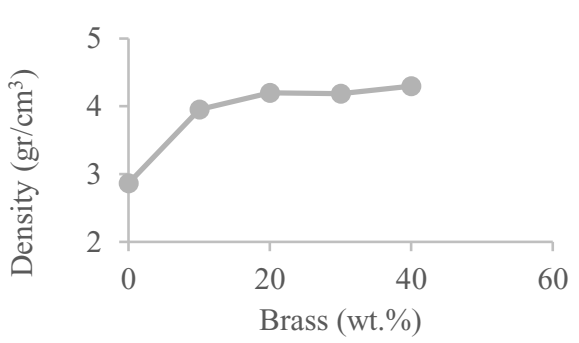

Fig. 2. Density of sintered specimen.

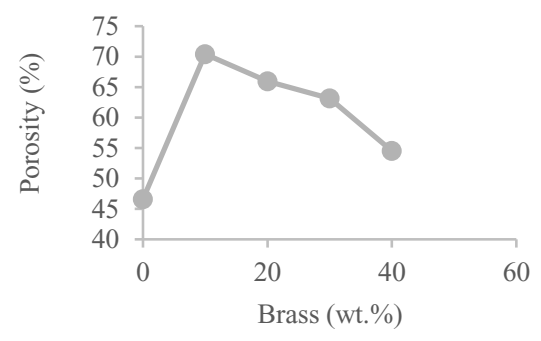

Fig. 3. Porosity of sintered specimen.

\section{Discussion}

The flexural strength of composite is increased by brass addition due to the higher tensile strength of brass compared with the matrix materials. The addition of brass was able to reduce the porosity of specimens, as can be observed from SEM results (Figure 4).

The observations of brass composite materials by using SEM show that the addition of $20 \mathrm{wt} . \%$ brass is indicated as the maximum of porosity (Figure 3). The addition of brass to ceramic materials (Clay, $\mathrm{TiO}_{2}, \mathrm{BC}$, and PVA) could influence the magnitude of the porosity of the composite material. The surface ratio between the composites without brass and the materials with the addition of $10 \mathrm{wt} . \%$ brass showed a significant difference. The addition of brass was able to change the surface became decreasing of porosity. While the addition of more brass showed subtle change of density. If the surface of the SEM result was observed further that the addition of more than $20 \mathrm{wt} . \%$ brass indicated the decreasing of porosity but had lower flexural strength. Addition of brass more than $20 \mathrm{wt} \%$ was already able to change the natural properties of ceramic (brittle) in this study. This is supported by some previous research [23-25]. 


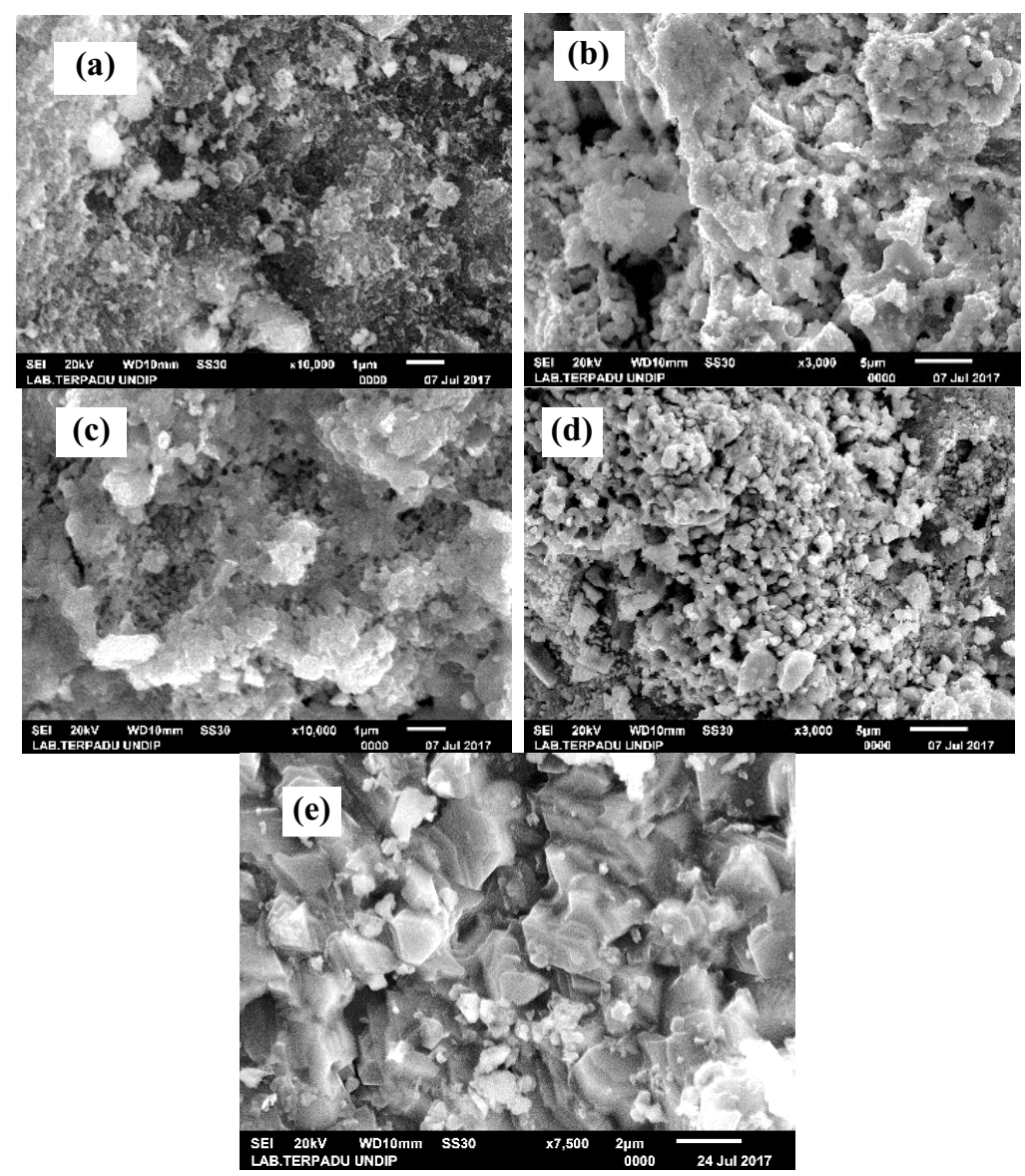

Fig. 4. SEM micrographs of addition of brass (a). 0 wt. \%, (b). 10 wt. \%, (c). 20 wt. \%, (d). 30 wt. $\%$, (e). 40 wt. $\%$.

\section{Conclusions}

Based on the data, that the flexural strength material has increased with the increasing of brass content up to $20 \mathrm{wt} . \%$. After reached $20 \mathrm{wt} . \%$ of brass content, the flexural strength of sintered specimen has decreased with increasing brass content.

The highest flexural strength is observed in $40 \mathrm{wt} . \%$ brass with $25.70 \mathrm{MPa}$. The increase of brass content in the ceramic matrix can decrease the amount of porosity so it potentially of composite.

Our special gratitude to the DRPM KemenristekDikti and Universitas Muhammadiyah Semarang on

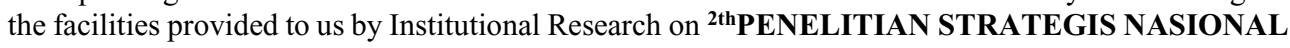
(PSN) SCHEME 2018.

\section{References}

1. N. L. Le and S. P. Nunes, Sustain. Mater. Technol., 7, 1-28 (2016)

2. A. Kayvani Fard et al., Materials, 11, 1 (2018)

3. H. J. Kim et al., Korean J Chem Eng, 18, 5 (2001) 
4. N. C. Nwogu, M. Kajama, and E. Gobina, Int. Jour. of Chem. and Molec. Engg, 9, 6 (2015)

5. M. N. Kajama, N. C. Nwogu, and E. Gobina, Int. J. Energy Prod. Manag., 1, 3 (2016)

6. S. L. Jaeweon Cho, Desalination, 160, 223-232 (2004)

7. B. K. Nandi, R. Uppaluri, and M. K. Purkait, Appl. Clay Sci., 42, 1 (2008)

8. H. Elomari et al., J. Asian Ceram. Soc., 5, 3 (2017)

9. A. Harabi, A. Guechi, and S. Condom, Procedia Eng., 33, 220-224 (2012)

10. F. Bouzerara, A. Harabi, S. Achour, and A. Larbot, J. Eur. Ceram. Soc., 26, 9 (2006)

11. S. Khemakhem, A. Larbot, and R. Ben Amar, Desalination, 200, 1 (2006)

12. A. Bouazizi et al., Appl. Clay Sci., 149, 127-135 (2017)

13. J. Fang, G. Qin, W. Wei, X. Zhao, and L. Jiang, Desalination, 311, 113-126 (2013)

14. M. H. Roushdy, S. K. Amin, S. A. El-Sherbiny, H. A. M. Abdallah, and M. F. Abadir, J. Solid Waste Technol. Manag., 42, 1 (2016)

15. I. Jedidi, S. Khemakhem, A. Larbot, and R. Ben Amar, Ceram. Int., 35, 2747-2753 (2009)

16. Amin, Abdallah, Roushdy, and Sherbiny, Int. J. Appl. Eng. Res., 11, 12 (2016)

17. M. Amin and M. Subri, MATEC Web Conf., 156, 08015 (2018)

18. M. Amin, M. Subri, and Jamasri, Mekanika, 15, 2 (2016)

19. M. Amin and M. Subri, Mekanika, 15, 2 (2016)

20. G. D. Quinn, B. T. Sparenberg, P. Koshy, L. K. Ives, S. Jahanmir, and D. D. Arola, "Flexural strength of ceramic and glass rods," J. Test. Eval., 37, 3 (2009)

21. M. Amin and M. Subri, AIP Conf. Proc., 1977, 1 (2018)

22. C. Schatz et al., Materials, 9, 3 (2016)

23. F. Z. Trindade et al., Appl. Adhes. Sci., 2, 1 (2014)

24. M. Chmielewski, J. Dutkiewicz, D. Kalinski, L. Litynska-Dobrzynska, K. Pietrzak, and A. Strojny-Nedza, Arch. Metall. Mater., 57, 3 (2012)

25. M. Marian, V. Raluca, B. Florin and M. Florin, U.P.B. Sci. Bull, Series B, 78 (2016) 